\title{
Immune alveolitis in interstitial lung disease: an attractive cytological profile in immunocompromised patients
}

Antoine Moui ( $\sim$ antoine.moui@chu-nantes.fr )

CHU Nantes: Centre Hospitalier Universitaire de Nantes https://orcid.org/0000-0002-0638-7619

\section{Stéphanie Dirou}

CHU Nantes: Centre Hospitalier Universitaire de Nantes

\section{Christine Sagan}

CHU Nantes: Centre Hospitalier Universitaire de Nantes

\section{Renan Liberge}

CHU Nantes: Centre Hospitalier Universitaire de Nantes

\section{Claire Defrance}

CHU Nantes: Centre Hospitalier Universitaire de Nantes

\section{Pierre-Paul Arrigoni}

CHU Nantes: Centre Hospitalier Universitaire de Nantes

\section{Olivier Morla}

CHU Nantes: Centre Hospitalier Universitaire de Nantes

\section{Christine Kandel-Aznar}

CHU Nantes: Centre Hospitalier Universitaire de Nantes

\section{Laurent Cellerin}

CHU Nantes: Centre Hospitalier Universitaire de Nantes

\section{Arnaud Cavailles}

CHU Nantes: Centre Hospitalier Universitaire de Nantes

\section{Emmanuel Eschapasse}

CHU Nantes: Centre Hospitalier Universitaire de Nantes

\section{Florent Morio}

CHU Nantes: Centre Hospitalier Universitaire de Nantes

\section{Pierre-Antoine Gourraud}

CHU Nantes: Centre Hospitalier Universitaire de Nantes

\section{Thomas Goronflot}

CHU Nantes: Centre Hospitalier Universitaire de Nantes

\section{Adrien Tissot}

CHU Nantes: Centre Hospitalier Universitaire de Nantes

\section{François-Xavier Blanc}




\section{Research article}

Keywords: Bronchoalveolar lavage, immune alveolitis, interstitial lung disease, immunosuppression, Pneumocystis pneumonia

Posted Date: August 4th, 2021

DOl: https://doi.org/10.21203/rs.3.rs-594950/v2

License: (a) (i) This work is licensed under a Creative Commons Attribution 4.0 International License. Read Full License

Version of Record: A version of this preprint was published at BMC Pulmonary Medicine on March 5th, 2022. See the published version at https://doi.org/10.1186/s12890-022-01871-w. 


\section{Abstract \\ Background}

Bronchoalveolar lavage (BAL) is a major diagnostic tool in interstitial lung disease (ILD). Its use remains largely quantitative, usually focused on cell differential ratio. However, cellular morphological features provide additional valuable information. The significance of the "immune alveolitis" cytological profile, characterized by lymphocytic alveolitis with activated lymphocytes and macrophages in epithelioid transformation or foamy macrophages desquamating in cohesive clusters with lymphocytes, remains unknown in ILD. Our objective was to describe patients' characteristics and diagnoses associated with an immune alveolitis profile in undiagnosed ILD.

\section{Methods}

We performed a monocentric retrospective observational study. Eligible patients were adults undergoing diagnostic exploration for ILD and whose BAL fluid displayed an immune alveolitis profile. For each patient, we collected clinical, radiological and biological findings as well as the final etiology of ILD.

\section{Results}

Between January 2012 and December 2018, 249 patients were included. Mean age was $57 \pm 16$ years, 140 patients (56\%) were men, and $65 \%$ of patients were immunocompromised. The main etiological diagnosis was Pneumocystis pneumonia (PCP) (24\%), followed by drug-induced lung disease (DILD) $(20 \%)$, viral pneumonia (14\%) and hypersensitivity pneumonitis (HP) (10\%). All PCP were diagnosed in immunocompromised patients while HP was found in only $8 \%$ of this subgroup. DILD and viral pneumonia were also commonly diagnosed in immunocompromised patients ( $94 \%$ and $80 \%$, respectively).

\section{Conclusion}

Our study highlights the additional value of BAL qualitative description in ILD. We suggest incorporating the immune alveolitis profile for the diagnosis and management of ILD, especially in immunocompromised patients, since it guides towards specific diagnoses.

\section{Background}

Interstitial lung diseases (ILD) have heterogeneous etiologies that have been classified by the American Thoracic Society (ATS) and the European Respiratory Society (ERS) $(1,2)$. The etiological diagnostic approach of ILD can be difficult and requires a rigorous clinical examination, serological tests and a high resolution lung CT scan with thin section $(<2 \mathrm{~mm})(3-7)$. A likely diagnosis can be suggested by specific 
CT scan patterns (8). In addition to CT scan analysis, a bronchoalveolar lavage (BAL) may be of great help to rule out differential diagnosis, in particular infectious diseases.

According to the nature of increased BAL fluid cell type (or alveolitis), different quantitative anatomopathological profiles have been identified: lymphocytic (>15\% lymphocytes), neutrophilic ( $>3 \%$ neutrophils) and eosinophilic alveolitis (>1\% eosinophils). However, none is specific of a single type of ILD (9). Typical BAL findings allow to obtain a formal diagnosis in some rare ILD such as pulmonary alveolar proteinosis, lipoid pneumonia and acute eosinophilic pneumonia (10). When analyzed together with clinical, biological and radiological data, examination of BAL has an added diagnostic value and guides towards a selection of disease. For example, lymphocytic alveolitis can be found in HP or sarcoidosis $(11,12)$, whereas neutrophilic alveolitis rather suggests idiopathic pulmonary fibrosis or asbestosis (9). However, apart from macrophages with smoking related inclusions or foamy macrophages, qualitative morphological analysis of BAL cells remains poorly described.

Immune alveolitis is a morphological profile of BAL fluid characterized by an abundant cellularity, with high lymphocytes rates between $30 \%$ and $80 \%$ (rather CD8+, activated lymphocytes with more abundant cytoplasm), some eosinophilic and neutrophilic polynuclear cells, particular mast cells and macrophages that can be described as 'foamy' and/or 'in epithelioid transformation', desquamating into cohesive clusters (13). There is minimal literature describing such profile in HP, reflecting the pulmonary immune reaction that occurs after allergen inhalation in sensitized individuals (14-16).

We hypothesized that immune alveolitis could also be taken into account in the diagnostic approach of ILD and restrict the suspected etiologies. We conducted the present study to evaluate the etiologies' frequency of ILD in patients with such immune alveolitis profile on BAL. Our secondary objective was to assess the association of clinical, radiological and biological factors to ILD final etiological diagnosis in this population.

\section{Methods}

\section{Study design and patients}

In this observational, descriptive, retrospective and monocentric study conducted at the University Hospital of Nantes, France, from January 2012 to December 2018, all adults who presented with ILD, detected on a chest radiograph or a CT scan, and who underwent a BAL that revealed an immune alveolitis profile were selected by automated file extraction of medical records. BAL was performed using $90 \mathrm{ml}$ of saline delivered into a lung segment affected by interstitial disease. BAL sample was sent for microbiological analyzes and for anatomopathological examination. An immune alveolitis profile on BAL was defined by the combination of lymphocytosis (greater than 10\%) and the following morphological criteria: activated lymphocytes, epithelioid transformation of macrophages, desquamation of macrophages into cohesive clusters, foamy macrophages (intra-cytoplasmic vacuoles). 
For this study, patients were considered as being immunocompromised if they had a solid organ or bone marrow transplantation, or received chemotherapy for solid or hematological cancer, or were treated by corticosteroids or any other immunosuppressive drugs.

\section{Endpoints}

The primary endpoint was the etiologies' frequency of ILD with an immune alveolitis profile on BAL. The final etiological diagnosis was collected in the electronic medical record until July 2019. Indeed, some etiologies were established several months after initial investigations. Some of these diagnoses may have been retained after multidisciplinary discussion or after a lung biopsy. For the uncertain diagnoses, all medical records were reviewed by an adjudication committee composed of a pulmonologist and a senior pathologist. The diagnosis of viral pneumonia was retained even in the absence of microbiological documentation when the clinical context, paraclinical data and clinical evolution were consistent with this diagnosis. In patients with intermediate fungal loads, PCP diagnosis was retained when the serum $\beta-D$ glucans were either positive or after multidisciplinary discussion when unavailable. As secondary endpoints, we analyzed clinical, radiological and biological characteristics of patients and assessed etiologies' frequency in particular subpopulations.

\section{Ethics}

The study protocol was submitted and approved by the « Délégation à la recherche clinique et à l'innovation (DRCl) » of our institution and by the "Institutional Review Board of the French-speaking Respiratory Medicine Society (Société de Pneumologie de Langue Française, SPLF)».

\section{Statistical analysis}

All analyses were conducted on the R software (version 3.3.0). Continuous variables were described according to their mean and standard deviation. Categorical variables were described as number and percentage. A univariate descriptive analysis was carried out to describe the overall population and to identify variables associated with the final etiological diagnosis (after excluding uncertain or infrequent diagnoses). We performed univariate analyses for each data item with the 5 most common etiologies. "Uncertain diagnoses" were excluded to minimize bias in the search for predictive factors. "Other diagnoses" and mycobacteria were excluded because of a small number of patients. We used the Chisquare independence test to assess the significance of the association between two categorical variables when validity test conditions were met. Otherwise, Fisher exact test was used. For continuous variables, the homogeneity of the variances and the normal distribution of the variables were first tested by the Levene and Shapiro-Wilk tests, respectively. Significance of differences in means was studied using Student's $t$-test when two means were compared or using a one-factor ANOVA when more than two means were compared. If conditions for applying these tests were not respected (normal distribution), we respectively used the Mann-Whitney-Wilcoxon test and the non-parametric Kruskal-Wallis test. We considered the statistical significance threshold for all tests at $5 \%$. Multiple testing issue was tackled using the Benjamini-Hochberg method by limiting false discovery rate to $5 \%$. 


\section{Results}

\section{Patients}

During the study period, 274 patients presented with immune alveolitis, as suggested by the pathologist. Among them, 25 were excluded because they did not meet the study criteria: 11 without ILD and 14 who were managed in another center and were only referred for bronchoscopy. Thus, 249 patients were analyzed.

Mean age of patients was $57 \pm 16$ years old and 140 (56\%) were men (Table 1). Ninety-eight patients $(40 \%)$ were current or former smokers. A total of 163 patients $(65 \%)$ had a history of cancer, transplantation or immunosuppressive therapy and were therefore considered as being immunocompromised. Corticosteroid was the most common immunosuppressive therapy (30\% of patients) with an average daily dose of $16.5 \mathrm{mg}$ (prednisone equivalent). PCP prophylaxis was given in 43 patients ( $17 \%$ of the general population and $26 \%$ of immunocompromised patients) and cotrimoxazole was the most frequently used drug (24 patients). 
Table 1

Clinical, biological and radiological characteristics of patients.

\section{Characteristics of patients}

Clinical

Age, years

Male

Smoking status

Smoker $(N A=3)$

Number of pack-years

Comorbidities

Immunocompromised

Solid cancer

Hematological cancer

Solid organ transplant

Bone marrow transplant

Connective tissue diseases

HIV positive

Treatments

Corticosteroid

Dose, $\mathrm{mg} /$ day

Methotrexate

Mycophenolate mofetil

Ciclosporin

Chemotherapy

Immunotherapy

Pneumocystis prophylaxis

Radiological

Lesions on chest CT $\operatorname{scan}(N A=21)$
Total $(\mathrm{N}=\mathbf{2 4 9})$

$57 \pm 16$

$140(56)$

$98(40)$

$21 \pm 18$

$163(65)$

65 (26)

$56(22)$

39 (16)

$24(10)$

$20(8)$

8 (3)

75 (30)

$16.5 \pm 16$

$18(7)$

$20(8)$

$20(8)$

$29(12)$

$11(4)$

$43(17)$

Note: Data are presented as mean \pm SD or $\mathrm{N}(\%)$. Abbreviations: BAL Bronchoalveolar lavage; SD Standard deviation; N number; NA not applicable 


\section{Characteristics of patients}

Ground glass opacification

Reticulation

Micronodules

Consolidation

Septa thickening

Mosaic attenuation

Bilateral lesions

Distribution $(N A=21)$

Diffuse

Lower lobes

Upper lobes

Biological

Serum biology

Leukocytes, giga/L $(N A=36)$

Neutrophils, giga/L $(N A=47)$

Lymphocytes, giga/L $(N A=47)$

Eosinophils, giga/L $(N A=48)$

Hemoglobin, $\mathrm{g} / \mathrm{dL}(\mathrm{NA}=36)$

Platelets, giga/L ( $N A=39)$

$\mathrm{CRP}, \mathrm{mg} / \mathrm{dL}(\mathrm{NA}=92)$

Bronchial fibroscopy

Bacteria

Mycobacteria $(N A=4)$

Positive viral PCR $(N A=18)$

Fungi

Pneumocystis cysts (direct examination)
Total $(\mathrm{N}=\mathbf{2 4 9})$

$179(79)$

88 (39)

$66(29)$

$62(27)$

$37(16)$

$11(5)$

$197(86)$

$136(60)$

54 (24)

$32(14)$
$8.0 \pm 6.0$

$5.5 \pm 4.0$

$1.6 \pm 3.7$

$0.18 \pm 0.21$

$12.1 \pm 2.2$

$278 \pm 561$

$65.4 \pm 73.2$

$37(15)$

7 (3)

$34(15)$

94 (38)

$17(7)$

Note: Data are presented as mean \pm SD or $\mathrm{N}(\%)$. Abbreviations: BAL Bronchoalveolar lavage; SD Standard deviation; N number; NA not applicable 


\begin{tabular}{|c|c|}
\hline Characteristics of patients & Total $(\mathrm{N}=\mathbf{2 4 9})$ \\
\hline Positive Pneumocystis PCR (NA = 75) & $89(51)$ \\
\hline \multicolumn{2}{|l|}{ Pneumocystis PCR copies $(N A=4)$} \\
\hline Colonization & $32(38)$ \\
\hline Intermediate & $25(29)$ \\
\hline Infection & $28(33)$ \\
\hline BAL cellularity, cells/ml & $245,692 \pm 350,317$ \\
\hline \multicolumn{2}{|l|}{ Cell populations on BAL, \% $(N A=4)$} \\
\hline Macrophages & $43 \pm 17$ \\
\hline Lymphocytes & $51 \pm 18$ \\
\hline Neutrophils & $5 \pm 8$ \\
\hline Eosinophils & $1.5 \pm 4$ \\
\hline \multicolumn{2}{|l|}{ Morphological anomalies on BAL, $(N A=1)$} \\
\hline Activated lymphocytes & $238(96)$ \\
\hline Macrophages into cohesive clusters & $245(99)$ \\
\hline Epithelioid transformation of macrophages & $240(97)$ \\
\hline Foamy macrophages & $185(75)$ \\
\hline $\begin{array}{l}\text { Note: Data are presented as mean } \pm \text { SD or } N \\
\text { Standard deviation; } N \text { number; NA not applic }\end{array}$ & onchoalveolar lavage; SD \\
\hline
\end{tabular}

\section{Clinical, radiological, biological and BAL features}

The most frequent clinical signs were dyspnea (75\%), cough (58\%) and fever (38\%). Extra-thoracic signs (skin, eye, joint, muscle) were not uncommon (15\%).

Radiological patterns were heterogeneous in these patients with immune alveolitis (Table 1). Ground glass opacities were the most frequently observed (79\%), preferentially bilateral (86\%) and diffuse (60\%). In addition, the 21 patients whose CT scan was not performed all exhibited an interstitial syndrome on chest radiography.

Blood cell counts were normal in most patients, notably with the absence of eosinophilia and with a lymphocyte rate within the lower limits of normal (Table 1). Pneumocystis jirovecii PCR was positive in half of the tested population ( $n=89$ patients). 
Anatomopathological analysis of BAL fluid found a high cellularity of $245,692 \pm 350,317$ cells $/ \mathrm{mL}$. Quantitative analysis of BAL cell populations revealed a lymphocytosis (51 $\pm 18 \%)$, a rate of macrophages reduced to $43 \pm 17 \%$ and a rate of neutrophils and eosinophils slightly higher than normal ( $5 \pm 8 \%$ and $1 \pm 4 \%$, respectively). Morphological analysis almost always showed activated lymphocytes (96\%), desquamative macrophages into cohesive clusters (99\%) and macrophages in epithelioid transformation (97\%) (Fig. 1). Presence of foamy or micro-vacuolated macrophages was frequent (75\%).

\section{Primary outcome}

Etiological diagnoses of ILD associated with an immune alveolitis profile are shown in Fig. 2 and Table 2. The most common diagnosis was Pneumocystis pneumonia in 59 patients (24\%), followed by DILD in 49 patients $(20 \%)$, everolimus being the most frequently involved drug ( $n=11$ patients), followed by nivolumab $(n=5)$ and methotrexate $(n=5)$. Amiodarone was associated with DILD in only 3 patients $(6 \%)$. Thirty-four patients ( $14 \%$ of the global population) had viral pneumonia with viral identification in half of cases, respiratory syncitial virus, coronavirus and rhinovirus being the most frequently identified viruses (Additional File 1). 
Table 2

Etiological diagnoses in the overall population.

\begin{tabular}{|ll|}
\hline Etiological diagnosis & Total (N = 249) \\
\hline Pneumocystis pneumonia & $59(24)$ \\
\hline Drug induced lung disease & $49(20)$ \\
\hline Viral pneumonia & $34(14)$ \\
\hline Uncertain diagnoses & $26(10)$ \\
\hline Hypersensitivity pneumonitis & $25(10)$ \\
\hline Granulomatosis & $25(10)$ \\
\hline Sarcoidosis & $19(8)$ \\
\hline Common variable immunodeficiency & $2(1)$ \\
\hline Other granulomatosis & $4(1)$ \\
\hline Other diagnoses & $17(7)$ \\
\hline Connective tissue disease & $5(2)$ \\
\hline Vasculitis & $3(1)$ \\
\hline Pulmonary graft versus host disease & $3(1)$ \\
\hline Bacteria (intracellular) & $2(1)$ \\
\hline Idiopathic nonspecific interstitial pneumonia & $1(0.5)$ \\
\hline Cryptogenic organizing pneumonia & $1(0.5)$ \\
\hline Lymphoma & $1(0.5)$ \\
\hline Silicosis & $1(0,5)$ \\
\hline Mycobacteria & $14(6)$ \\
\hline Mycobacterium tuberculosis & $11(5)$ \\
\hline Non-tuberculous mycobacterium & $3(1)$ \\
\hline Data are presented as N (\%). Abbreviations: SD Standard deviation; N number \\
\hline
\end{tabular}

Ten percent of patients were diagnosed with HP $(n=25)$, granulomatosis $(n=25)$, or had uncertain diagnosis despite assessment by the adjudication committee $(n=26)$ (Table 2).

\section{Immunocompromised subpopulations}

Among the 163 immunocompromised patients, the main diagnosis was Pneumocystis pneumonia $(\mathrm{n}=$ 59 patients, $36 \%$ ). All patients with a final diagnosis of PCP were immunocompromised compared to $8 \%$ 
of patients with HP.

Twenty-six percent of the immunocompromised patients received PCP prophylaxis and 13 patients were diagnosed with PCP despite such prophylaxis. Four of them were taking cotrimoxazole with uncertain compliance while the 9 others received nebulized pentamidine or atovaquone. In immunocompromised patients, the second most common diagnosis was DILD (46 patients, 28\%). Viral pneumonia was diagnosed in 27 patients (16\%). The distribution of diagnoses was similar for patients receiving corticosteroids (75 patients, $30 \%$ of the global population). Among them, $36 \%$ had a daily dose $>10 \mathrm{mg}$ equivalent prednisone and 26 patients received PCP prophylaxis (35\%). No patient taking corticosteroids was diagnosed with HP.

\section{Associated factors with the etiological diagnosis}

Clinical, radiological and biological factors associated with the final etiological diagnosis are shown in Table 3, Additional File 2 and 3. In univariate analysis, age, solid cancer, hematological cancer, solid organ or bone marrow transplantation, corticosteroid therapy, chemotherapy, or immunotherapy, immunosuppression, PCP prophylaxis, the presence of fever, dyspnea or extra-thoracic signs were all associated with immune alveolitis (Table 3). Radiological factors associated with the etiological diagnosis were the presence of ground glass opacities, micronodules, condensations or a mosaic attenuation (Additional File 2). Finally, biological factors associated with this profile were white and red blood cells count, and the positivity of microbiological examinations (Additional File 3). 
Table 3

Clinical characteristics of patients according to etiology.

\begin{tabular}{|c|c|c|c|c|c|c|}
\hline $\begin{array}{l}\text { Clinical characteristics }(\mathrm{N}= \\
192)\end{array}$ & $\begin{array}{l}\text { PCP } \\
(\mathrm{N}= \\
59)\end{array}$ & $\begin{array}{l}\text { DILD } \\
(\mathrm{N}= \\
49)\end{array}$ & $\begin{array}{l}\text { Viral } \\
\text { pneumonia } \\
(\mathrm{N}=34)\end{array}$ & $\begin{array}{l}\mathrm{HP} \\
(\mathrm{N}= \\
25)\end{array}$ & $\begin{array}{l}\text { Granuloma- } \\
\text { tosis } \\
(\mathrm{N}=25)\end{array}$ & $P *$ \\
\hline Age, years & $\begin{array}{l}57 \pm \\
16\end{array}$ & $\begin{array}{l}65 \pm \\
13\end{array}$ & $54 \pm 17$ & $\begin{array}{l}60 \pm \\
14\end{array}$ & $50 \pm 15$ & 0.001 \\
\hline Male & $\begin{array}{l}29 \\
(49)\end{array}$ & $\begin{array}{l}26 \\
(53)\end{array}$ & $17(50)$ & $\begin{array}{l}16 \\
(64)\end{array}$ & $20(80)$ & 0.08 \\
\hline \multicolumn{7}{|l|}{ Smoking status } \\
\hline Smoker $(N A=3)$ & $\begin{array}{l}24 \\
(40)\end{array}$ & $\begin{array}{l}21 \\
(43)\end{array}$ & $10(29)$ & $8(32)$ & $12(48)$ & 0,5 \\
\hline Pack-years & $\begin{array}{l}18 \pm \\
14\end{array}$ & $\begin{array}{l}30 \pm \\
30\end{array}$ & $23 \pm 18$ & $\begin{array}{l}14 \pm \\
16\end{array}$ & $21 \pm 16$ & 0.5 \\
\hline \multicolumn{7}{|l|}{ Comorbidities } \\
\hline Immunocompromised & $\begin{array}{l}59 \\
(100)\end{array}$ & $\begin{array}{l}46 \\
(94)\end{array}$ & $27(80)$ & $2(8)$ & $6(24)$ & 0.0001 \\
\hline Solid cancer & $\begin{array}{l}18 \\
(32)\end{array}$ & $\begin{array}{l}27 \\
(56)\end{array}$ & $7(21)$ & $5(20)$ & $1(4)$ & 0.0005 \\
\hline Hematological cancer & $\begin{array}{l}22 \\
(37)\end{array}$ & $7(14)$ & $15(45)$ & $0(0)$ & $0(0)$ & 0.0001 \\
\hline Solid organ transplant & $\begin{array}{l}19 \\
(31)\end{array}$ & $7(15)$ & $7(21)$ & $0(0)$ & $1(4)$ & 0.0008 \\
\hline Bone marrow transplant & $9(15)$ & $0(0)$ & $8(23)$ & $0(0)$ & $0(0)$ & 0.0004 \\
\hline Connective tissue disease & $6(11)$ & $6(13)$ & $1(3)$ & $1(4)$ & $0(0)$ & 0.3 \\
\hline HIV & $4(7)$ & $1(2)$ & $0(0)$ & $0(0)$ & $0(0)$ & 0.3 \\
\hline \multicolumn{7}{|l|}{ Treatments } \\
\hline Corticosteroids & $\begin{array}{l}31 \\
(52)\end{array}$ & $\begin{array}{l}17 \\
(34)\end{array}$ & $12(35)$ & $0(0)$ & $5(20)$ & 0.0005 \\
\hline Dose, mg/day & $\begin{array}{l}20 \pm \\
19\end{array}$ & $\begin{array}{l}13 \pm \\
10\end{array}$ & $12 \pm 9$ & / & $11 \pm 3$ & 0.7 \\
\hline Methotrexate & $6(10)$ & $6(12)$ & $2(6)$ & $0(0)$ & $2(8)$ & 0.4 \\
\hline
\end{tabular}

Data are presented as mean \pm SD or $\mathrm{N}(\%)$. * Multiple testing issue was tackled using BenjaminiHochberg method by limiting False Discovery Rate to $5 \%$. Statistical significance threshold was at $3 \%$.

Abbreviations: SD Standard deviation; N number; NA not applicable; PCP Pneumocystis pneumonia; DILD Drug-induced lung disease; HP Hypersensitivity pneumonitis. 


\begin{tabular}{|c|c|c|c|c|c|c|}
\hline $\begin{array}{l}\text { Clinical characteristics }(\mathrm{N}= \\
\text { 192) }\end{array}$ & $\begin{array}{l}\text { PCP } \\
(\mathrm{N}= \\
59)\end{array}$ & $\begin{array}{l}\text { DILD } \\
(\mathrm{N}= \\
49)\end{array}$ & $\begin{array}{l}\text { Viral } \\
\text { pneumonia } \\
(\mathrm{N}=34)\end{array}$ & $\begin{array}{l}\mathrm{HP} \\
(\mathrm{N}= \\
25)\end{array}$ & $\begin{array}{l}\text { Granuloma- } \\
\text { tosis } \\
(\mathrm{N}=25)\end{array}$ & $P *$ \\
\hline Mycophenolate mofetil & $9(15)$ & $2(4)$ & $4(12)$ & $0(0)$ & $0(0)$ & 0.03 \\
\hline Ciclosporin & $6(10)$ & $4(8)$ & $8(23)$ & $0(0)$ & $1(4)$ & 0.04 \\
\hline Chemotherapy & $\begin{array}{l}12 \\
(20)\end{array}$ & $\begin{array}{l}14 \\
(28)\end{array}$ & $2(5)$ & $0(0)$ & $0(0)$ & 0.0002 \\
\hline Immunotherapy & $3(5)$ & $7(14)$ & $0(0)$ & $0(0)$ & $0(0)$ & 0.02 \\
\hline Pneumocystis prophylaxis & $\begin{array}{l}13 \\
(21)\end{array}$ & $3(6)$ & $15(44)$ & $0(0)$ & $1(4)$ & 0.0001 \\
\hline \multicolumn{7}{|l|}{ Physical examination } \\
\hline Fever & $\begin{array}{l}39 \\
(66)\end{array}$ & $\begin{array}{l}15 \\
(30)\end{array}$ & $27(79)$ & $2(8)$ & $2(8)$ & 0.0001 \\
\hline $\begin{array}{l}\text { Deterioration of general } \\
\text { condition }\end{array}$ & $9(15)$ & $5(10)$ & $6(17)$ & $4(16)$ & $3(12)$ & 0.9 \\
\hline Cough & $\begin{array}{l}31 \\
(52)\end{array}$ & $\begin{array}{l}28 \\
(57)\end{array}$ & $21(62)$ & $\begin{array}{l}18 \\
(72)\end{array}$ & $11(44)$ & 0.3 \\
\hline Dyspnea & $\begin{array}{l}48 \\
(81)\end{array}$ & $\begin{array}{l}44 \\
(89)\end{array}$ & $28(82)$ & $\begin{array}{l}21 \\
(84)\end{array}$ & $14(56)$ & 0.02 \\
\hline Expectorations & $\begin{array}{l}12 \\
(20)\end{array}$ & $7(14)$ & $9(26)$ & $7(28)$ & $4(16)$ & 0.5 \\
\hline Extra-thoracic signs & $2(3)$ & $4(8)$ & $2(6)$ & $4(16)$ & $14(56)$ & 0.0001 \\
\hline \multicolumn{7}{|c|}{$\begin{array}{l}\text { Data are presented as mean } \pm \text { SD or } N(\%) . * \text { Multiple testing issue was tackled using Benjamini- } \\
\text { Hochberg method by limiting False Discovery Rate to } 5 \% \text {. Statistical significance threshold was at } 3 \% \text {. }\end{array}$} \\
\hline $\begin{array}{l}\text { Abbreviations: SD Standard } \\
\text { DILD Drug-induced lung dise }\end{array}$ & viation & numbe & A not applic & ; PCP & umocystis $\mathrm{pr}$ & onia; \\
\hline
\end{tabular}

\section{Discussion}

In this retrospective analysis of 249 patients with an immune alveolitis profile on BAL, the main five ILD's etiologies were Pneumocystis pneumonia (24\%), followed by DILD (20\%), viral pneumonia (14\%), HP $(10 \%)$ and granulomatosis (10\%). Immunocompromised patients represented $65 \%$ of the overall population. In this subgroup, the most frequent diagnosis was by far PCP and HP diagnosis was retained in only two cases.

To the best of our knowledge, the diagnostic contribution of the immune alveolitis morphological profile has not been previously described in patients with PCP. However, lymphocytic alveolitis is commonly reported in PCP and prognosis relating to BAL cellular analysis has been evaluated (17). Lymphocytosis 
was found with an average rate of $31 \%$ in 166 non-HIV infected patients with PCP (18), which is consistent with our results. In addition, BAL cell type profile seems to have a prognostic value. In non-HIV infected patients, Lee et al. evaluated the prognosis impact of BAL cell profile in PCP. Alveolar lymphocytes appeared to be lower in patients with severe PCP compared to those with mild and moderate disease (18). Recently, Gaborit et al. analyzed prognostic factors in immunocompromised patients with Pneumocystis pneumonia (19). The presence of an immune alveolitis profile on BAL was an independent protective factor for mortality at 90 days. Based on these observations, additional investigations to evaluate the prognostic contribution of this profile in other ILDs are warranted.

Immune alveolitis profile on BAL has been yet poorly explored. It is usually considered as an immunoallergic profile, which refers to the pathophysiology that was mainly described in HP during the 90's (1416). Recent ATS/ERS guidelines focus on lymphocyte counts and recommend to obtain BAL fluid in cases with suggestive diagnosis of non-fibrotic HP (20). Even though a $40 \%$ lymphocyte threshold has been identified as an important item for the diagnosis of HP (21), ATS/ERS guidelines do not set a lymphocyte threshold. Furthermore, immune alveolitis profile has not been detailed but could provide an additional value in distinguishing HP from others ILD related entities.

Many heterogeneous BAL cytological features can be associated with pulmonary drug toxicity and hamper BAL contribution in the diagnostic approach of DILD (22), Morphological description of BAL cells had focused on intra alveolar foamy macrophages in amiodarone pneumonitis (23). Apart from amiodarone (implicated in only $6 \%$ of DILD in our series), drugs that were the most frequently involved in our study were everolimus, followed by nivolumab and methotrexate.

The cytological profile of BAL has been well described in sarcoidosis and is characterized by a rather moderate lymphocytic alveolitis (about $30 \%$ ) that may reach higher levels $(50 \%)$ when the disease is active (24). The significant proportion of granulomatosis associated with an immune alveolitis profile, and especially sarcoidosis, is an unexpected result of our study. In some patients with a past history of sarcoidosis, immune alveolitis was found in a context of disease recurrence, leading to a resumption of immunosuppressive therapies. In view of these findings, immune alveolitis would be more likely present in the early and active phases of the disease.

Ten percent of the population did not have a definite etiological diagnosis at the end of data collection, which highlights the difficulty associated to the ILD diagnostic work-up. BAL is a recognized diagnostic tool to investigate ILD (9). When BAL is interpreted in combination with clinical data and HRCT findings, it holds a great potential in establishing ILD's etiology. Validation of a new BAL morphological pattern will hopefully aim to reduce ILD differential diagnoses and limit the need for surgical lung biopsy. Indeed, the 5 most common diagnoses accounted for nearly $80 \%$ of the final etiologies in our study. In addition, when the immunocompromised status was considered, the main final etiologies were reduced to three: PCP, DILD and viral pneumonia.

Results from univariate analysis highlight clinical, radiological or biological factors that can help in the diagnostic process and consequently that need to be sought. For example, fever or the absence of extra 
thoracic signs seem indicative factors to reduce ILD etiologies, while corticosteroids use appears to be negatively associated with HP.

Our study had some limitations. Its retrospective design led to missing data, especially regarding the search for different antibodies (e.g., anti-nuclear, or serum precipitins). Another study limitation was a potential selection bias related to its monocentricity. Indeed, our tertiary hospital is a reference center for kidney, heart, lung and bone marrow transplants. As a consequence, $65 \%$ of our population was immunocompromised. This parameter had obviously an impact on the frequency of final etiologies, especially for PCP.

\section{Conclusion}

In summary, this study highlights the additional value of BAL qualitative description in ILD with a detailed characterization of immune alveolitis, a poorly studied BAL profile. We suggest incorporating this profile for the diagnosis and management of ILD, especially in immunocompromised patients. Indeed, the presence of an immune alveolitis profile reduces the etiological possibilities and should systematically lead to exclude the diagnosis of PCP. The diagnostic contribution of immune alveolitis is inseparable of clinical, radiological and biological data that must be taken into account in a multidisciplinary diagnostic process.

\section{Abbreviations}

ATS

American Thoracic Society

BAL

Bronchoalveolar lavage

DILD

Drug-induced lung disease

ERS

European Respiratory Society

HP

Hypersensitivity pneumonitis

ILD

Interstitial lung disease

PCP

Pneumocystis pneumonia

\section{Declarations}

\section{Ethics approval and consent to participate}


The protocol of the study was submitted and validated by the « Délégation à la recherche clinique et à l'innovation (DRCl) » of the University Hospital of Nantes, and by the « Institutional Review Board of the French-speaking Respiratory Medicine Society (Société de Pneumologie de Langue Française, SPLF) ».

Guarantor statement: Antoine MOUI and Stéphanie DIROU take responsibility for the content of the manuscript, including the data and analysis.

\section{Consent for publication}

Not applicable

\section{Availability of data and materials}

The datasets used and/or analyzed during the current study are available from the corresponding author on reasonable request.

\section{Competing interests}

The authors declare that they have no competing interests.

Funding: This work did not benefit from any funding.

\section{Author's contributions}

AMo collected, analyzed the data and wrote the first draft version of the manuscript. SD equally contributed to the writing of the manuscript. CS and FXB designed the study and supervised the manuscript writing. TG and PAG analyzed the data. RL, CD, PPA, OM, CKA, LC, AC, FM, EE and AT edited the manuscript. All authors approved the final version of the manuscript and vouch for the accuracy of the reported data.

\section{Acknowledgements}

Not applicable

\section{Author's information}

Antoine Moui: antoine.moui@chu-nantes.fr

Stéphanie Dirou: stephanie.dirou@chu-nantes.fr

Christine Sagan: christine.sagan@chu-nantes.fr

Renan Liberge: renan.liberge@chu-nantes.fr

Claire Defrance: claire.defrance@chu-nantes.fr 
Pierre-Paul Arrigoni: pierrepaul.arrigoni@chu-nantes.fr

Olivier Morla: olivier.morla@chu-nantes.fr

Christine Kandel-Aznar: christine.kandel@chu-nantes.fr

Laurent Cellerin: laurent.cellerin@chu-nantes.fr

Arnaud Cavailles: arnaud.cavailles@chu-nantes.fr

Emmanuel Eschapasse: emmanuel.eschapasse@chu-nantes.fr

Florent Morio: florent.morio@chu-nantes.fr

Pierre-Antoine Gourraud: pierreantoine.gourraud@chu-nantes.fr

Thomas Goronflot: thomas.goronflot@chu-nantes.fr

Adrien Tissot: adrien.tissot@chu-nantes.fr

François-Xavier Blanc: xavier.blanc@chu-nantes.fr

\section{Footnotes}

Not applicable

\section{References}

1. American Thoracic Society/European Respiratory Society International Multidisciplinary Consensus Classification of the Idiopathic Interstitial Pneumonias. This Joint Statement of the American Thoracic Society (ATS), and the European Respiratory Society (ERS) was adopted by the ATS Board of Directors, June 2001 and by The ERS Executive Committee, June 2001. Am J Respir Crit Care Med. 2002;165(2):277-304.

2. Travis WD, Costabel U, Hansell DM, King TE, Lynch DA, Nicholson AG, et al. An official American Thoracic Society/European Respiratory Society statement: Update of the international multidisciplinary classification of the idiopathic interstitial pneumonias. Am J Respir Crit Care Med. 2013;188(6):733-48.

3. Atzeni F, Gerardi MC, Barilaro G, Masala IF, Benucci M, Sarzi-Puttini P. Interstitial lung disease in systemic autoimmune rheumatic diseases: a comprehensive review. Expert Rev Clin Immunol. 2018;14(1):69-82.

4. Mittoo S, Gelber AC, Christopher-Stine L, Horton MR, Lechtzin N, Danoff SK. Ascertainment of collagen vascular disease in patients presenting with interstitial lung disease. Respir Med. 2009;103(8):1152-8. 
5. Cotton CV, Spencer LG, New RP, Cooper RG. The utility of comprehensive autoantibody testing to differentiate connective tissue disease associated and idiopathic interstitial lung disease subgroup cases. Rheumatology. 2017;56(8):1264-71.

6. Lynch DA, Sverzellati N, Travis WD, Brown KK, Colby TV, Galvin JR, et al. Diagnostic criteria for idiopathic pulmonary fibrosis: a Fleischner Society White Paper. Lancet Respir Med. 2018;6(2):13853.

7. Raghu G, Remy-Jardin M, Myers JL, Richeldi L, Ryerson CJ, Lederer DJ, et al. Diagnosis of idiopathic pulmonary fibrosis. An official ATS/ERS/JRS/ALAT clinical practice guideline. Am J Respir Crit Care Med. 2018;198(5):e44-68.

8. Collins J. CT signs and patterns of lung disease. Radiol Clin North Am. 2001;39(6):1115-35.

9. Meyer KC, Raghu G, Baughman RP, Brown KK, Costabel U, du Bois RM, et al. An official American Thoracic Society clinical practice guideline: The clinical utility of bronchoalveolar lavage cellular analysis in interstitial lung disease. Am J Respir Crit Care Med. 2012;185(9):1004-14.

10. Wells AU. The clinical utility of bronchoalveolar lavage in diffuse parenchymal lung disease. Eur Respir Rev. 2010;19(117):237-41.

11. Morell F, Roger A, Reyes L, Cruz MJ, Murio C, Muñoz X. Bird fancier's lung: a series of 86 patients. Med (Baltim). 2008;87(2):110-30.

12. Spagnolo P, Rossi G, Trisolini R, Sverzellati N, Baughman RP, Wells AU. Pulmonary sarcoidosis. Lancet Respir Med. 2018;6(5):389-402.

13. Sagan $\mathrm{C}$, Bégueret $\mathrm{H}$. Cas pratiques: du lavage broncho-alvéolaire à la biopsie pulmonaire. Ann Pathol. 2009;29(5):103-4.

14. Cordeiro C, Jones J, Alfaro T, Ferreira A. Bronchoalveolar lavage in occupational lung diseases. Semin Respir Crit Care Med. 2007;28(5):504-13.

15. Costabel U. The alveolitis of hypersensitivity pneumonitis. Eur Respir J. 1988;1(1):5-9.

16. Hughes DA, Haslam PL. Effect of smoking on the lipid composition of lung lining fluid and relationship between immunostimulatory lipids, inflammatory cells and foamy macrophages in extrinsic allergic alveolitis. Eur Respir J. 1990;3(10):1128-39.

17. Tamai K, Tachikawa R, Tomii K, Nagata K, Otsuka K, Nakagawa A, et al. Prognostic value of bronchoalveolar lavage in patients with non-HIV pneumocystis pneumonia. Intern Med. 2014;53(11):1113-7.

18. Lee W, Chung WS, Hong K-S, Huh J. Clinical usefulness of bronchoalveolar lavage cellular analysis and lymphocyte subsets in diffuse interstitial lung diseases. Ann Lab Med. 2015;35(2):220-5.

19. Gaborit BJ, Tessoulin B, Lavergne R-A, Morio F, Sagan C, Canet E, et al. Outcome and prognostic factors of Pneumocystis jirovecii pneumonia in immunocompromised adults: a prospective observational study. Ann Intensive Care. 2019;9(1):131.

20. Raghu G, Remy-Jardin M, Ryerson CJ, Myers JL, Kreuter M, Vasakova M, et al. Diagnosis of hypersensitivity pneumonitis in adults. An official ATS/JRS/ALAT clinical practice guideline. Am J 
Respir Crit Care Med. 2020;202(3):e36-69.

21. Morisset J, Johannson KA, Jones KD, Wolters PJ, Collard HR, Walsh SLF, et al. Identification of diagnostic criteria for chronic hypersensitivity pneumonitis. An international modified Delphi survey. Am J Respir Crit Care Med. 2018;197(8):1036-44.

22. Costabel U, Uzaslan E, Guzman J. Bronchoalveolar lavage in drug-induced lung disease. Clin Chest Med. 2004;25(1):25-35.

23. Larsen BT, Vaszar LT, Colby TV, Tazelaar HD. Lymphoid hyperplasia and eosinophilic pneumonia as histologic manifestations of amiodarone-induced lung toxicity. Am J Surg Pathol. 2012;36(4):50916.

24. Drent M, Mansour K, Linssen C. Bronchoalveolar lavage in sarcoidosis. Semin Respir Crit Care Med. 2007;28(5):486-95.

\section{Figures}
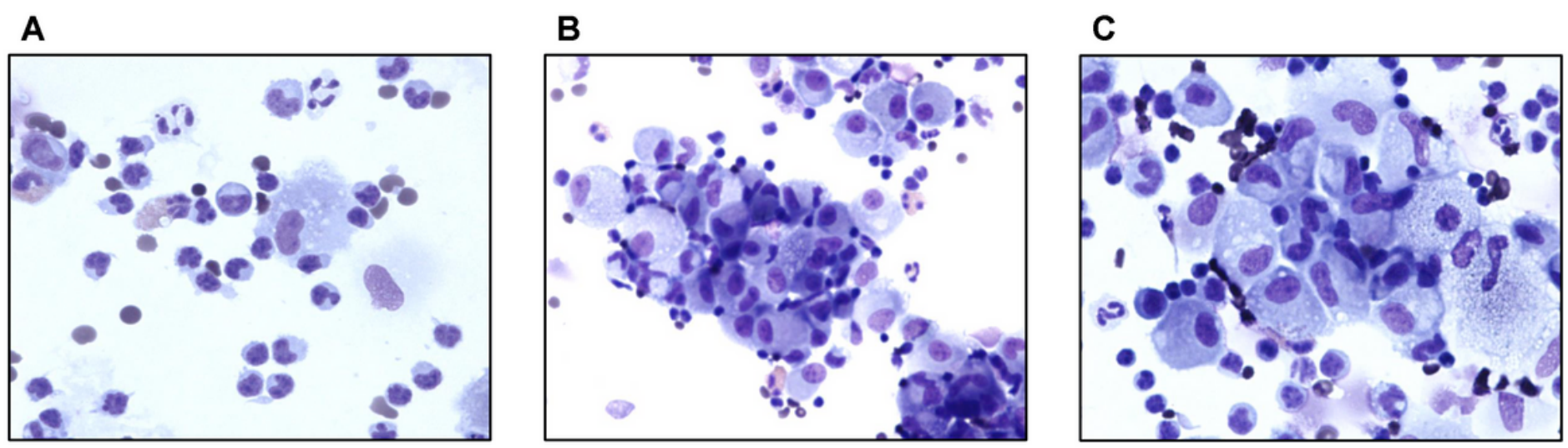

\section{Figure 1}

Typical morphological characteristics of immune alveolitis on bronchoalveolar lavage. Activated lymphocytes (A), desquamation of macrophages into cohesive clusters (B), epithelioid transformation of macrophages and foamy macrophages (intra-cytoplasmic vacuoles) (C). 


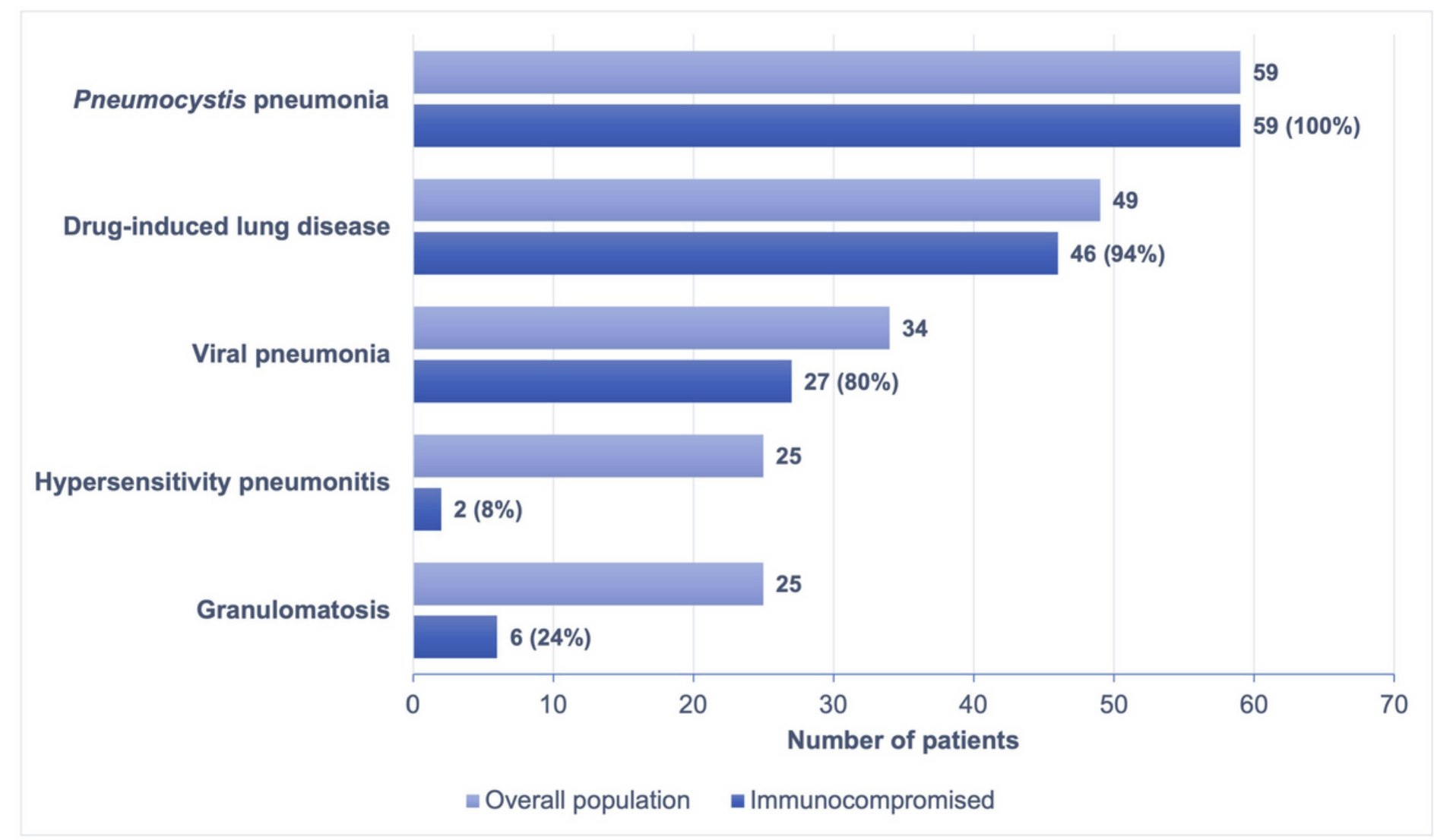

Figure 2

Distribution of etiological diagnoses in the overall population and immunocompromised patients.

\section{Supplementary Files}

This is a list of supplementary files associated with this preprint. Click to download.

- AdditionnalFile1.docx

- AdditionnalFile2.docx

- AdditionnalFile3.docx 